\title{
Etiology of heart failure in the emergency department of a tertiary cardiac centre of Nepal
}

\author{
Miqdhaadh Shareef, ${ }^{1}$ Man Bahadhur KC, ${ }^{2}$ Roshan Raut, ${ }^{2}$ Anish Hirachan, ${ }^{1}$ Bishal KC, ${ }^{1}$ Amit K. Agarwal, ${ }^{1}$ \\ Ram Kishor Shah, ${ }^{1}$ Chandra Mani Adhikari, ${ }^{2}$
}

Department of Cardiology, National Academy of Medical Sciences, Bir Hospital, Kathmandu

Department of Cardiology, Shahid Gangalal National Heart Centre, Kathmandu

Correspoding Author: Miqdhaadh Shareef,

Department of Cardiology,

National Academy of Medical Sciences, Bir Hospital, Kathmandu, Nepal

E-mail: dr.miqdhaadh@gmail.com

\section{Abstract}

Background and Aims :Heart failure is a major global health problem, but studies on prevalence of heart disease in Nepal are sparse. The aim of this study is to describe the etiology of heart failure patients in emergency department of Shahid Gangalal National Heart Centre.

Methods: This was a single centre, prospective, observational study, conducted in the Emergency Department of National Heart Centre, from 1st May to 30th August 2016. All $(n=591)$ consecutive patients with clinical diagnosis of heart failure were evaluated.

Results: The mean age of the patients was $56.48 \pm 19.44$ years, with $45.9 \%$ males. $31.3 \%$ had atrial fibrillation. The commonest cause of heart failure was rheumatic heart disease $(25.1 \%)$, followed by dilated cardiomyopathy $(22.8 \%)$, and coronary artery disease $(18.1 \%)$. The commonest causes in the age group $\leq 44$ years were rheumatic heart disease $(61.9 \%)$, and congenital heart disease $(11.0 \%)$. Commonest causes in the age groups $45-64$ years and $\geq 65$ years were dilated cardiomyopathy (29.0\% and $26.4 \%$, respectively) and coronary artery disease $(22.3 \%$ and $24.3 \%$, respectively). The commonest causes in male was dilated cardiomyopathy $(26.9 \%)$ and in female it was rheumatic heart disease $(31.6 \%)$.

Conclusion: Rheumatic heart disease, dilated cardiomyopathy and coronary artery disease are the commonest cause of heart failure. Appropriate prevention strategies focused at these causes of heart failure are required to decrease the burden of heart failure in Nepal.

Keywords : Cornary artery disease; Dilated cardiomyopathy; Heart failure; Rheumatic Heart disease.

DOI: http://dx.doi.org/10.3126/njh.v14i2.18494

\section{Introduction}

Heart failure (HF) is a major global health problem..$^{1,2}$ The majority of information on HF comes from high-income countries. ${ }^{3}$ The existing data suggest that there are substantial inter-regional and intra-regional variations. ${ }^{4,5,6}$ Yet systematic evidence for its current burden to patients and health services is limited. ${ }^{7,8,9}$

Studies on prevalence of heart disease in Nepal are sparse. A study by Shakya et al. concluded that the prevalence is higher in urban areas than rural areas..$^{10}$ Dubey et al. described the profile of HF patients in Bharatpur, ${ }^{11}$ and later Shrestha et al. had described the profile in the western regions. ${ }^{12}$ In both studies, the commonest cause of HF was coronary artery disease.

Considering the differences in clinical and social backgrounds and management of $\mathrm{HF}$ across geographic regions, the aim of this study is to describe the various causes of HF in patients who present to the emergency department of Shahid Gangalal National Heart Centre, Kathmandu, Nepal.

\section{Methods}

This was a single centre, prospective, observational study. Starting from 1st of May to 30th of August 2016, 591 consecutive patients who presented to the Emergency Department of Shahid Gangalal National Heart Centre with a clinical diagnosis of HF, diagnosed by the Framingham Congestive Heart Failure Criteria, ${ }^{13}$ were included in this study. This criteria diagnoses a patients as congestive $\mathrm{HF}$ if he/she has 2 major criteria or 1 major and 2 minor criteria. The major criteria includes paroxysmal nocturnal dyspnea or orthopnea, neck vein distension, rales, radiographic cardiomegaly, acute pulmonary edema, S3 gallop, increased venous pressure more than $16 \mathrm{mmH}_{2} \mathrm{O}$, hepatojugular reflux, weight loss more than $4.5 \mathrm{~kg}$ in 5 days in response to treatment. The minor critera include bilateral ankle edema, nocturnal cough, dyspnea on ordinary exertion, hepatomegaly, pleural effusion, decrease in vital capacity by $1 / 3$ from maximum recorded, tachycardia with rate more than $120 / \mathrm{min}$. 
If a patient presented to the Emergency Department twice during the data collection period, the patient's data was included only for the first visit, and the subsequent visits were not included. An informed consent was taken from all the patients. This study was approved by the Institutional Review Board of National Academy of Medical Sciences.

All the required data were collected by filling up a questionnaire, and the data were analyzed using Microsoft Excel 2007 and Statistical Package for Social Sciences (SPSS) version 20. Descriptive statistics were calculated using mean and standard deviation.

\section{Results}

A total of 591 consecutive patients were evaluated. The age of the patients varied from 12 to 94 years with a mean age of 56.48 \pm 19.44 years. There were 271 male patients $(45.9 \%)$ and 320 female patients $(54.1 \%)$ as shown in Table 1.

\begin{tabular}{|ll|}
\hline Table 1: Baseline characteristics & \\
\hline Characteristic & $\begin{array}{l}\text { Number of patients } \\
(\mathbf{n}=591)\end{array}$ \\
\hline Age (years \pm SD) & $56.48 \pm 19.44$ \\
\hline Gender: & $271(45.9 \%)$ \\
\hline Males, n (\%) & $320(54.1 \%)$ \\
\hline Females, $\mathrm{n}(\%)$ & $189(31.9 \%)$ \\
\hline Medications at presentation: & $110(18.6 \%)$ \\
\hline Antiplatelet agents, $\mathrm{n}(\%)$ & $178(30.1 \%)$ \\
\hline Statins, $\mathrm{n}(\%)$ & $121(20.5 \%)$ \\
\hline ACEi/ARB, $\mathrm{n}(\%)$ & $49(8.3 \%)$ \\
\hline Betablockers, $\mathrm{n}(\%)$ & $254(43.0 \%)$ \\
\hline Calcium channel blockers, $\mathrm{n}(\%)$ & $160(27.1 \%)$ \\
\hline Diuretics, $\mathrm{n}(\%)$ & $95(16.1 \%)$ \\
\hline Aldosterone antagonist, $\mathrm{n}(\%)$ & \\
\hline Digoxin, $\mathrm{n}(\%)$ & $406(68.7 \%)$ \\
\hline Rhythms: & $185(31.3 \%)$ \\
\hline Sinus rhythm, $\mathrm{n}(\%)$ & \\
\hline Atrial fibrillation, $\mathrm{n}(\%)$ &
\end{tabular}

Among these patients with $\mathrm{HF}, 31.9 \%$ patients were on an antiplatelet agent, $18.6 \%$ on a statin, $30.1 \%$ on an angiotensin converting enzyme inhibitor (ACEi) or an angiotensin receptor blocker (ARB), $20.5 \%$ on a beta-blocker, $8.3 \%$ on a calcium channel blocker, $43.0 \%$ on a diuretic, $27.1 \%$ on an aldosterone antagonist, and $16.1 \%$ were on digoxin. Out of these patients, 185 patients $(31.3 \%)$ had atrial fibrillation (AF), and the remaining $68.7 \%$ patients were in sinus rhythm.

The commonest cause of HF observed in this study was rheumatic heart disease, which was seen in 148 patients (25.1\%). This was followed by dilated cardiomyopathy in 135 patients $(22.8 \%)$, coronary artery disease in 107 patients (18.1\%), non-rheumatic valvular heart disease in 63 patients $(10.7 \%)$, hypertensive heart disease in 59 patients $(10.0 \%)$, cor-pulmonale in $38 \%$ patients $(6.4 \%)$, congenital heart disease in 19 patients (3.2\%), peripartum cardiomyopathy in 16 patients $(2.7 \%)$, and hypertrophic cardiomyopathy in 6 patients $(1.0 \%)$ as shown in Table 2.

\begin{tabular}{|ll|}
\hline Table 2: Frequency of various causes of HF & \\
\hline Cause & Number (\%) \\
\hline Coronary artery disease & $107(18.1 \%)$ \\
\hline Hypertensive heart disease & $59(10.0 \%)$ \\
\hline Dilated cardiomyopathy & $135(22.8 \%)$ \\
\hline Hypertrophic cardiomyopathy & $6(1.0 \%)$ \\
\hline Rheumatic heart disease & $148(25.1 \%)$ \\
\hline Non-rheumatic valvular heart disease & $63(10.7 \%)$ \\
\hline Congenital heart disease & $19(3.2 \%)$ \\
\hline Cor-pulmonale & $38(6.4 \%)$ \\
\hline Peripartum cardiomyopathy & $16(2.7 \%)$ \\
\hline
\end{tabular}

When the cause of HF was evaluated according to different age groups, the commonest cause of heart failure in the young age group of $\leq 44$ years was rheumatic heart disease (96 patients, $61.9 \%$ ), followed by congenital heart disease (17 patients, $11.0 \%)$. The commonest cause in the age group from $45-64$ years was dilated cardiomyopathy (56 patients, $29.0 \%$ ) followed by coronary artery disease (43 patients, $22.3 \%$ ). This was also true for the older age group of patients $\geq 65$ years (26.4\% for dilated cardiomyopathy, and $24.3 \%$ for coronary artery disease) as shown in Fig 1.

Figure 1: Causes of HF according to age group

\section{Cause of HF according to age group}

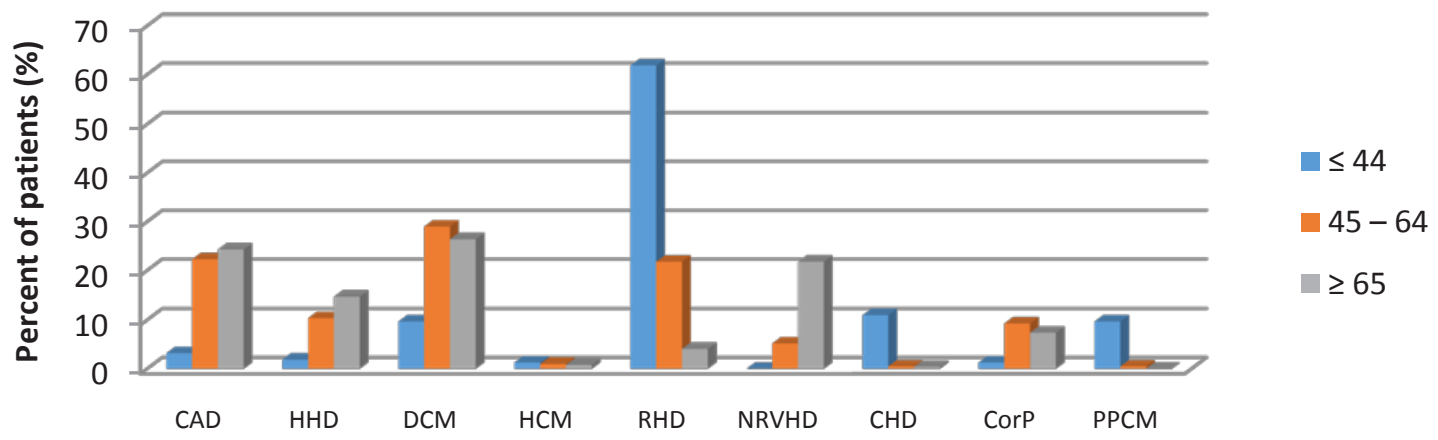

$C A D=$ coronary artery disease; HHD = hypertensive heart disease; DCM = dilated cardiomyopathy; HCM = hypertrophic cardiomyopathy; RHD = rheumatic heart disease; $N R V H D=$ non-rheumatic valvular heart disease; $C H D=$ congenital heart disease; Cor $P=$ cor-pulmonale; $P P C M=$ peripartum cardiomyopathy 
The mean age of the patients presenting with coronary artery disease was $65.14 \pm 11.86$ years, for hypertensive heart disease was

$67.41 \pm 12.20$ years, dilated cardiomyopathy $62.36 \pm 15.62$ years, hypertrophic cardiomyopathy $54.83 \pm 19.99$ years, rheumatic heart disease $38.78 \pm 14.66$ years, non-rheumatic valvular heart disease $72.78 \pm 10.01$ years, congenital heart disease $27.26 \pm$ 16.59

years, cor-pulmonale $63.18 \pm 13.48$ years, and for peripartum cardiomyopathy it was $27.63 \pm 9.18$ years as shown in Figure 2 .

Figure 2: Mean age of presentation with different causes of $\mathrm{HF}$

\section{Mean age of presentation with different causes of HF}

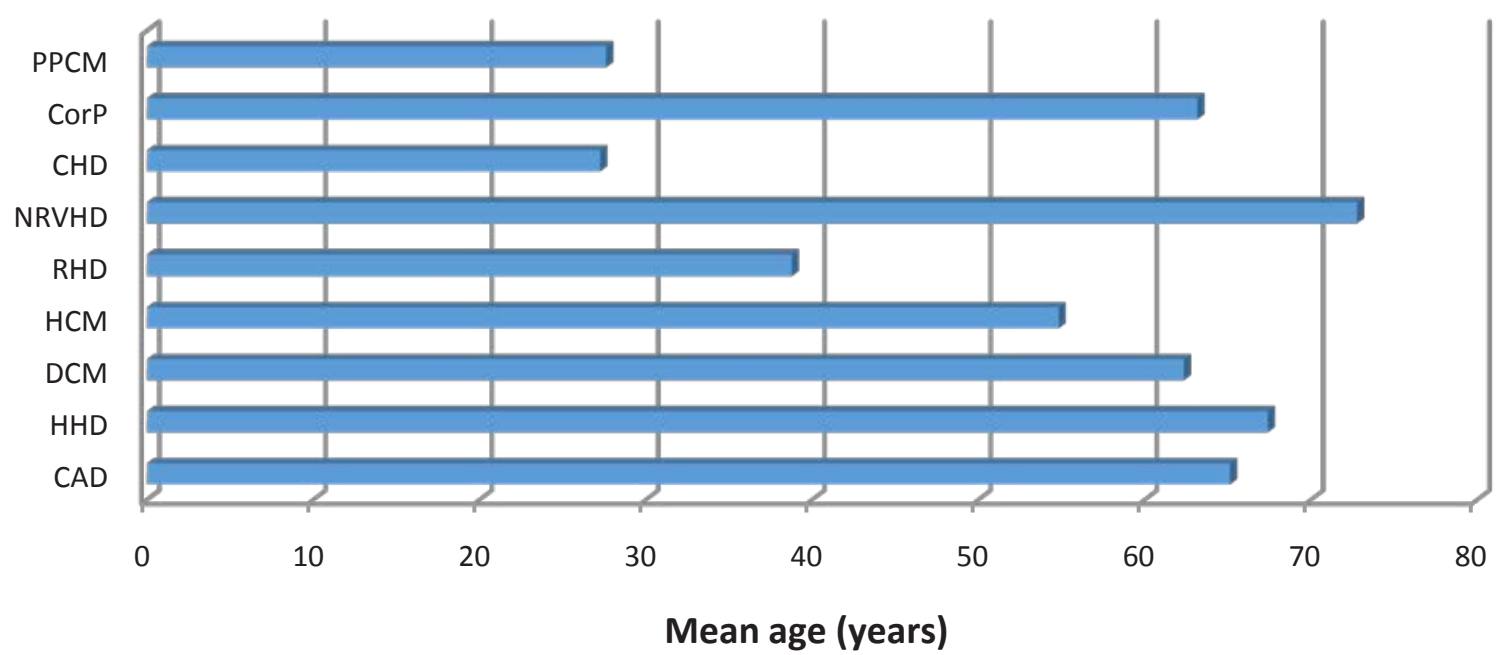

$C A D=$ coronary artery disease $H H D=$ hypertensive heart disease; DCM = dilated cardiomyopathy; HCM = hypertrophic cardiomyopathy; RHD = rheumatic heart disease; NRVHD = non-rheumatic valvular heart disease; $C H D=$ congenital heart disease; Cor $P=$ cor-pulmonale; PPCM = peripartum cardiomyopathy

When the causes were evaluated according to gender, the commonest cause in males was found to be dilated cardiomyopathy (73 patients, $26.9 \%$ ) followed by coronary artery disease (71 patients, $26.2 \%$ ). In females the commonest cause was rheumatic heart disease (101 patients, $31.6 \%$ ) followed by dilated cardiomyopathy (62 patients, $19.4 \%$ ) as shown in Table 3.

\begin{tabular}{|c|c|c|}
\hline Cause & Male $\mathrm{N}=271$ & Female $\mathrm{N}=320$ \\
\hline $\begin{array}{l}\text { Coronary artery } \\
\text { disease, } \mathrm{n}(\%)\end{array}$ & $71(26.2 \%)$ & $36(11.3 \%)$ \\
\hline Hypertension, n (\%) & $25(9.2 \%)$ & $34(10.5 \%)$ \\
\hline $\begin{array}{l}\text { Dilated } \\
\text { cardiomyopathy, n } \\
(\%)\end{array}$ & $73(26.9 \%)$ & $62(19.4 \%)$ \\
\hline $\begin{array}{l}\text { Hypertrophic } \\
\text { cardiomyopathy, n } \\
(\%)\end{array}$ & $3(1.1 \%)$ & $3(0.9 \%)$ \\
\hline $\begin{array}{l}\text { Rheumatic heart } \\
\text { disease, } \mathrm{n}(\%)\end{array}$ & $47(17.3 \%)$ & $101(31.6 \%)$ \\
\hline $\begin{array}{l}\text { Non-rheumatic } \\
\text { valvular heart disease, } \\
\mathrm{n}(\%)\end{array}$ & $32(11.8 \%)$ & $31(9.7 \%)$ \\
\hline $\begin{array}{l}\text { Congenital heart } \\
\text { disease, } \mathrm{n}(\%)\end{array}$ & $6(2.2 \%)$ & $13(4.1 \%)$ \\
\hline Cor-pulmonale, n (\%) & $14(5.2 \%)$ & $24(7.5 \%)$ \\
\hline $\begin{array}{l}\text { Peripartum } \\
\text { cardiomyopathy }\end{array}$ & $0(0.0 \%)$ & $16(5.0 \%)$ \\
\hline
\end{tabular}

\section{Discussion}

HF is a growing cause of hospitalization around the world. With increase in both survival rate and prevalence of coronary artery disease, HF has gained epidemic proportions in developed countries. In developing countries, like Nepal, rheumatic heart disease leading to valvular lesions is still considered as one of the commonest causes of $\mathrm{HF}$ admission. Having a prevalence of over 5.8 million in the USA, and over 23 million worldwide, HF is a major public health issue. With a lifetime risk of one in five, $\mathrm{HF}$ can originate from $\mathrm{CAD}$, high blood pressure, rheumatic heart disease, or other causes like cardiomyopathies, congenital heart disease, endocarditis and myocarditis. It not only is still a common reason for urgent admission to hospital but also is a major cause of morbidity and mortality. ${ }^{11}$

The Everest study demonstrated significant differences in HF severity, etiology, and management among different continents and regions in a large, international trial in acute HF syndromes. Their data demonstrated that despite efforts to select for a fairly homogenous study population, important differences in etiology, severity, management, and outcomes existed. The etiology and management of HF may vary by region and is difficult to control. ${ }^{14}$

The mean age of patients presenting with $\mathrm{HF}$ in this study was $56.48 \pm 19.44$, which is consistent with previous reports. In the ADHERE-AP (Asian-Pacific) Study, it was reported that patients registered in South-East Asia were generally younger (median age: 53, 60, 61, 67 and 71 years for Philippines, Indonesia, Malaysia, Thailand and Singapore, respectively) as compared with those in East Asia (median age: 77 years for both Hong Kong and Taiwan) and in Australia (median age: 77 years). ${ }^{15}$

Rheumatic heart disease continues to be a major health problem in developing countries (especially Africa and Asia) where it is still an important cause of HF, often in the young. ${ }^{9}$ Our 
finding is similar to their study, with an overall $25.1 \%$ presenting with $\mathrm{HF}$ due to rheumatic heart disease, and increases to $61.9 \%$ of the patients when the patients $\leq 44$ years were considered. Mendez et al. further noted in their study that, in all countries undergoing epidemiological transition, coronary artery disease is increasingly important as a cause of HF. In our study, the overall frequency of presentation with HF due to coronary artery disease was $18.1 \%$, increasing with age to $22.3 \%$ in the patients aged 45 to 64 years, and to $24.3 \%$ in patients $\geq 65$ years of age. Efforts spent on primary prevention of these conditions may, therefore, result in considerable savings on health care costs considering that the ill-effects of hypertension and rheumatic fever are felt during the productive years of life. ${ }^{16}$ The findings of Mendez et al. were also consistent with two studies done in Nepal previously. One study done in Bharatpur, Nepal, showed that the causes of HF were coronary artery disease $(36.5 \%)$, rheumatic heart disease $(25.5 \%)$, dilated cardiomyopathy $(14.5 \%)$, cor-pulmonale $(12.2 \%)$, hypertensive heart disease $(8.6 \%)$, and congenital heart disease $(2.7 \%) .{ }^{11} \mathrm{~A}$ study done in the western region of Nepal by Shrestha et al. found that ischemic heart disease $(29.5 \%)$ was still the commonest cause of $\mathrm{HF}$ followed by hypertensive heart disease (24.6\%). ${ }^{12}$

The effect of the epidemiologic transition varies not only among countries but also among regions, communities or ethnicities in the same country, making it difficult to generalize evidence obtained not only from Western countries but also from Asian countries. Considering the relatively younger age of patients with heart failure and larger population at risk for HF in Asian countries as compared with Western countries, the socioeconomic and clinical effects of heart failure are estimated to be particularly large in Asia. ${ }^{17}$ Therefore, further studies to identify the different causes of HF in different regions and ethnicities of Nepal are needed to fully understand the impact of heart failure in the country.

\section{Conclusions}

Rheumatic heart disease, dilated cardiomyopathy and coronary artery disease are the commonest causes of $\mathrm{HF}$ in our center. Appropriate prevention strategies are required to decrease the burden of HF in Nepal.

\section{References}

1. Ambrosy AP, Fonarow GC, Butler J, et al. The global health and economic burden of hospitalizationsfor heart failure lessons learned from hospitalized heart failure registries. J Am CollCardiol. 2014;63:1123-1133. https://doi.org/10.1016/j. jacc.2013.11.053

2. Cook C, Cole G, Asaria P, et al. The annual global economic burden of heart failure. Int J Cardiol. 2014;17:368-376. https://doi.org/10.1016/j.ijcard.2013.12.028

3. Moran AE, Oliver JT, Mirzaie M, et al. Assessing the global burden of ischemic heart disease: Part 1: Methods for a systematic review of the global epidemiology of ischemic heart disease in 1990 and 2010. Glob Heart. 2012;7(4):315329. https://doi.org/10.1016/j.gheart.2012.10.004

4. Khatibzadeh S, Farzadfar F, Oliver J, et al. Worldwide risk factors for heart failure: a systematic review and pooled analysis. Int J Cardiol. 2013;168:1186-1194. https://doi. org/10.1016/j.ijcard.2012.11.065

5. Howlett JG, Ezekowitz JA, Podder M, et al. Global variation in quality of care among patients hospitalized with acute heart failure in an international trial - Findings from the Acute Study Clinical Effectiveness of Nesiritide in Decompensated Heart Failure Trial (ASCEND-HF). CircCardiovascQual Outcomes. 2013;6:534-542. https://doi.org/10.1161/ CIRCOUTCOMES.113.000119

6. Kristensen SL, Kober L, Jhund PS, et al. International geographic variation in event rates in trials of heart failure with preserved and reduced ejection fraction. Circulation. 2015;131:43-53. https://doi.org/10.1161/ CIRCULATIONAHA.114.012284

7. Mosterd A, Hoes AW. Clinical epidemiology of heart failure. Heart. 2007;93:1137-1146. https://doi.org/10.1136/ hrt.2003.025270

8. Bui AL, Horwich TB, Fonarow GC. Epidemiology and risk profile of heart failure. Nat Rev Cardiol. 2011;8(1):30-41. https://doi.org/10.1038/nrcardio.2010.165

9. Mendez GF, Cowie MR. The epidemiological features of heart failure in developing countries: a review of the literature. Int J Cardiol. 2001;80:213-219. https://doi. org/10.1016/S0167-5273(01)00497-1

10. Shakya S, Sharma D, Bhatta YD. Current scenario of heart diseases in Nepal: At a glance. Nepalese Heart Journal. 2011;8:23-26

11. Dubey L, Sharma SK, Chaurasia AK. Clinical profile of patients hospitalized with heart failure in Bharatpur, Nepal. Journal of Cardiovascular and Thoracic Research. 2012;4:103-105

12. Shrestha UK, Alurkar VM, Baniya R, et al. Profiles of heart failure in the western region of Nepal: prognostic implications of the MELD-XI score. Intern Med Inside. 2015;3:1-7. https://doi.org/10.7243/2052-6954-3-1

13. McKee PA, Castelli WP, McNamara PM, et al. The natural history of congestive heart failure: the Framingham study. N Engl J Med. 1971;285:1441-1446. https://doi.org/10.1056/ NEJM197112232852601

14. Blair JEA, Zannad F, Konstam MA, et al. Continental differences in clinical characteristics, management, and outcomes in patients hospitalized with worsening heart failure - Results from the EVEREST (Efficacy of Vasopressin Antagonism in Heart Failure: Outcome Study with Tolvaptan) program. J Am CollCardiol. 2008;52:16401648. https://doi.org/10.1016/j.jacc.2008.07.056

15. Atherton JJ, Hayward CS, Ahmed WAW, et al. Patient characteristics from a regional multicenter database of acute decompensated heart failure in Asia Pacific (ADHERE International - Asia Pacific). J Cardiac Fail. 2012;18:82-88. https://doi.org/10.1016/j.cardfail.2011.09.003

16. Amoah AGB, Kallen C. Aetiology of heart failure as seen from a national cardiac referral centre in Africa. Cardiology. 2000;93:11-18. https://doi.org/10.1159/000006996

17. Sakata Y, Shimokawa H. Epidemiology of heart failure in Asia. Circ J. 2013;77:2209-2217. https://doi.org/10.1253/ circj.CJ-13-0971
Cite this article as: Miqdhaadh Shareef, Man Bahadhur KC, Roshan Raut, et al. Etiology of heart failure in the emergency department of a tertiary cardiac centre of Nepal. Nepalese Heart Journal 2017; 14(2): 1-4. http://dx.doi.org/10.3126/njh. v14i2.18494 